\title{
Association Between Community Environment and Dependency Among the Elderly From a Service Provision Perspective
}

\section{YiYang Pan}

Zhejiang University

\section{Yuan Chen}

Zhejiang University

PingYu Cui

Zhejiang University

\section{Nuremaguli WaiLi}

Zhejiang University

Ying Li ( $\nabla$ ying_li@zju.edu.cn )

Zhejiang University https://orcid.org/0000-0001-8953-2166

Research article

Keywords: dependency, place, community environment, resource dependence, elderly

Posted Date: January 15th, 2021

DOI: https://doi.org/10.21203/rs.3.rs-146099/v1

License: (c) (i) This work is licensed under a Creative Commons Attribution 4.0 International License. Read Full License 


\section{Abstract}

Background: The prevalence of dependency is high among the elderly worldwide and increases with increasing life expectancy. The objective of this study was to explore from the perspective of resource demand the association between community environmental resources and dependency among the elderly.

Methods: The study was designed as a population-based cross-sectional study. A total of 950 participants aged $\geq 60$ years from 22 locations in China were selected using a complex multistage sampling design. All data were collected using questionnaires and face-to-face interviews. The dependency was assessed using the Chinese version of the Minnesota Multiphasic Personality InventoryII. The community environment was assessed using 43 items. Logistic regression analysis was used to evaluate the association between the community environment and dependency. Cluster analysis was used and demonstrated that dependency was mainly associated with community primary preventive care service resources.

Results: In the analysis result, both age-specific and social support levels-stratified results showed that the dependency associated with community environmental resources differed among the elderly by age group and level of social support.

Conclusions: The levels of dependency were significantly associated with community environment resources. Our results suggest that the dependent on local environment resources may consider as the resource needs among elderly.

\section{Background}

Owing to the accelerating aging of the global population, the realization of healthy active aging has become a common concern worldwide [1,2]. As the elderly age and their physical function declines, the increasing prevalence of their dependency leads to increasing demand for medical care and social services, substantially challenging the individual and social service system and becoming an urgent problem requiring immediate solutions [3-5].

Traditional dependency is a personality disorder in which individuals are highly dependent on others to fulfill their emotional and physical needs, resulting in the gradual loss of autonomy [6, 7]. The causes of dependency are not very clear, and its classification and consequences are complex. A recent study demonstrated that markers of biological age, such as leukocyte telomere length, are associated with dependency, but health and the consequences of poor health and dependency are more intimately linked with social, economic, and environmental factors, especially for the elderly [8-10]. Many studies have demonstrated the adverse outcomes caused by different dependency objects such as people, substances, and behaviors, which can lead to nursing dependency, alcohol dependency, and sleep dependency. Dependency can also lead to increases in the consequences of diseases such as depression, heart disease, and all-cause mortality [11-14]. 
The theory of place dependency was proposed more than 30 years ago, but quantitative studies on the association between person and place dependency have rarely been conducted [15]. Because the performance of dependency is multifaceted, and it is difficult to measure and evaluate, and the consequences of dependency are also complex, which may be positive or negative [16]. Place dependency is usually understood as follows: an individual experiencing a place becomes dependent on the place because the place can fulfill his or her needs, creating dentification, belonging, and other emotional aspects of the performance. Place dependency is a type of functional dependency, reflecting the importance of the resources and facilities provided. Some studies have shown that place dependency is positively associated with the service quality of the place [17].

Recently, the interest in resource dependency among fields of community psychology, environmental psychology, and gerontology to explore the provision of community service resources has been increasing [18-20]. The theory of resource dependency emphasizes that the survival of an organization needs to absorb resources from the surrounding environment and needs to depend on and interact with the surrounding environment to achieve survival or improve the quality of life. Research has demonstrated that in the past two decades, the number of nursing homes in the world has decreased significantly, and an increasing number of elderly individuals are living in their homes, leading to complex nursing needs for families and community services [21, 22].

The World Health Organization suggests that the best way to support the elderly in the community is to integrate all types of resources, adapt to the actual social environment of the elderly, and provide targeted health services; these integrated services should be prioritized over other services [23]. However, how to achieve or solve the complex problem, including improving the understanding of community needs, remains unclear. According to our review of the literature, the complex association between dependency and the community environment has not been investigated through complete data analysis. Therefore, the purpose of answering the research questions in this study was to provide evidence for further research into and development of effective strategies to improve the community environment and services on the basis of the needs of the elderly, to improve community resources.

\section{Methods}

\section{Study design}

This study used a cross-sectional design based on the project "Accessibility Evaluation of Health-Related Resources for the Elderly."

\section{Setting}

Sampling was conducted in 22 locations in four provinces (Zhejiang, Heilongjiang, Xinjiang, and Sichuan) in China from July 2019 to November 2019.

\section{Participants}


A total of 950 general residents aged $\geq 60$ years were selected using a multistage sampling design by calculation. A population-based survey was conducted to assess the health and health-related resources of accessibility of the elderly from multiple aspects: social, economic, behavioral and psychological, medical, and environmental.

We excluded subjects who were unable to complete the questionnaire. All participants provided written informed consent before participation in this study. The study was approved by the institutional review board at the School of Medicine, Zhejiang University.

\section{Data collection}

Data were collected using questionnaires provided to the participants during face-to-face interviews. The nine-part questionnaire comprised 428 items. The main content comprised demographic characteristics, general health status and behavior habits, environmental and community health service resources, psychological resources, and activities of daily living assessment. The duration of the interview was supposed to be approximately 45 to 60 minutes for the majority of participants.

The general characteristics were the participants' age, gender, ethnicity, income, education level, selfreported chronic disease status, disease history, daily habits, and physical activity level. Environmental assessment is generally conducted from three aspects: physical, social, and psychological. In this study, the environmental assessment was determined by assessing the housing environment, surrounding housing environment, and community environment. The community environmental resources were assessed using 44 items.

The Chinese version of the dependency scale used in this study was validated by the standardized Minnesota Multiphasic Personality Inventory-II. The dependency scale comprised 57 items. The raw score was converted into a standardized T-score. Dependency was defined as a standardized T-score greater than or equal to 60 points. Social resource status was assessed using the Chinese version of the questionnaires of the Older American Resources and Services (OARS) social resource scale, which comprised three dimensions: social interaction, availability of social support and practical assistance, and interpersonal relation. The ratings were summed to yield a total score. A high level of social support was defined as an OARS score greater than or equal to 11 points. Participants' personality characteristics were identified using the Eysenck Personality Questionnaire (EPQ).

\section{Statistical analysis}

Statistical analysis was restricted to the 913 participants with complete questionnaires and dependency assessment data. Descriptive statistics were used to describe the general characteristics of the study participants.

We performed cluster analysis for the community environmental variables using the oblique principle component method to analyze the association between dependency and community environmental factors. Univariate analyses were performed to determine whether the variable was added into the cluster 
analysis model with a power of $80 \%$ at a significance level of 0.05 . The R-squared with own cluster and Rsquared with $1-R^{2}$ ratio were used to determine the number of clusters. The cluster trees is output by the program "proc tree."

The logistic regression model was used to evaluate the association between dependency and community environment resources and the associated risk factors. The dependency score was treated as a binary variable. If a participant's T-score on the dependency scale was greater than or equal to 60 points, then they will be regarded as a dependent individual in the binary dependent variable of the logistic regression model, expressed by "1," and "0" was used for scores lower than 60 points. The model included all the community environment variables that were significant in the univariate analysis, adjusted for important confounding factors such as age, gender, income satisfaction, alcohol use, smoking status, physical activity, chronic disease status, social support level, and EPQ scores.

We conducted two separate logistic regression models by the age and levels of social support, to compare the association between dependency and community environment resources in different age groups and levels of social support. The age was divided into two categories: under 70 years and over or equal to 70 years. The levels of social support were divided into two categories: less than 11 points and greater or equal to 11 points by the median. Models were also adjusted for gender, income satisfaction, alcohol use, smoking status, physical activity, chronic disease status, and EPQ scores. All analyses were performed using SAS for Windows (version 9.4).

\section{Results}

The characteristics of the study participants are presented in Table 1, and the highlights are as follows: $37.7 \%$ were aged over 70 years, $58.4 \%$ were female, $41.6 \%$ were male, approximately $19.6 \%$ were nonmarried, and $66.7 \%$ had been diagnosed with one or more chronic diseases. $12.8 \%$ of the participants were assessed as having dependency, and no significant difference between males and females was observed. 
Table 1

Characteristics of study participants in the study

\begin{tabular}{|c|c|c|}
\hline Variable categories & n & $\%$ \\
\hline \multicolumn{3}{|c|}{ Characteristic variables (n, \%) } \\
\hline \multicolumn{3}{|l|}{ Sex } \\
\hline Male & 380 & 41.6 \\
\hline Female & 533 & 58.4 \\
\hline \multicolumn{3}{|l|}{ Age (yr) } \\
\hline $60-69$ & 569 & 62.3 \\
\hline$\geq 70$ & 344 & 37.7 \\
\hline \multicolumn{3}{|l|}{ Marital status } \\
\hline Married & 734 & 80.4 \\
\hline Non-married & 179 & 19.6 \\
\hline \multicolumn{3}{|l|}{ Education levels (yr) } \\
\hline $0-6$ & 176 & 19.3 \\
\hline $7-9$ & 353 & 38.7 \\
\hline $10-12$ & 211 & 23.1 \\
\hline $13+$ & 173 & 18.9 \\
\hline \multicolumn{3}{|l|}{ Individual income } \\
\hline$¥ 0$ to 1,999 & 550 & 60.2 \\
\hline$¥ 2,000$ to 3,999 & 230 & 25.2 \\
\hline$¥ 4,000$ to 5,999 & 87 & 9.5 \\
\hline$¥ 6,000$ and Over & 46 & 5.1 \\
\hline \multicolumn{3}{|l|}{ Smoking status } \\
\hline Yes & 126 & 13.8 \\
\hline No & 787 & 86.2 \\
\hline \multicolumn{3}{|l|}{ Alcohol use } \\
\hline Yes & 186 & 20.4 \\
\hline GDS-15: the 15-item & essiol & Scale \\
\hline EPQ: the Eysenck & 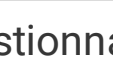 & \\
\hline
\end{tabular}




\begin{tabular}{|lcc|}
\hline Variable categories & $\mathbf{n}$ & $\%$ \\
\hline No & 727 & 79.6 \\
\hline Physical activity & & \\
\hline Yes & 360 & 39.4 \\
\hline No & 553 & 60.6 \\
\hline Chronic disease status & & \\
\hline Yes & 611 & 66.9 \\
\hline No & 302 & 33.1 \\
\hline Measured Variables (Mean, SD) & & \\
\hline Dependency scores & 43.4 & 12.8 \\
\hline GDS-15 scores & 3.4 & 3.0 \\
\hline EPQ scores & 22.3 & 4.1 \\
\hline GDS-15: the 15-item Geriatric Depression Scale \\
\hline EPQ: the Eysenck Personality Questionnaire \\
\hline
\end{tabular}

The tree graph by cluster analysis is presented in Fig. 2 . The 34 variables of the community environment that were significantly associated with dependency were divided into six categories. The first category can be summarized as follows: community primary preventive care service resources (e.g., diet and health guidance for elderly and chronic patients), contracted family doctor services, screening for common diseases, regular home visits for the elderly living alone and disabled, the utilization of electronic health records, and holding regular lectures on general health knowledge. Other community environment variables can be classified into the following categories: utilization of and satisfaction with community services, community culture, and basic living facilities; psychological, cognitive, and comprehensive nursing resources; employment and caregiver guidance organizations; and home living support services. We put the score of dependency into the cluster analysis model to investigate the association between the score of dependency and the environmental resources of the community. The score of dependency was classified into the category of community primary preventive care service resources, and no significant change in those variables in another category was observed.

Table 2 presents the odds ratios (ORs) of the community environment resources for dependency using logistic regression models. The participants who responded "yes" to "Do you think it is necessary for community medical staff to assess your health status" and "if there is a short-term care home for the elderly in your community" were compared with the participants who responded "no" to the same items. The result was as follows: these community environment variables were significantly positively 
associated with levels of dependency in the logistic regression analysis, namely the OR was $2.10(95 \% \mathrm{Cl}$, 1.33-3.34, $P=0.001)$ and $2.40(95 \% \mathrm{Cl}, 1.40-4.09, P=0.001)$. Other community environmental resources such as the community geriatric ward冈regular lectures on health knowledge, and screening for common diseases were also positively associated with levels of dependency: the OR was $1.97(95 \% \mathrm{Cl}$, $1.23-3.18, P=0.005) \otimes 1.50(95 \% \mathrm{Cl}, 1.06-2.14, P=0.023)$, and $1.56(95 \% \mathrm{Cl}, 1.05-2.34, P=0.029)$, respectively. The community cultural activity center, supermarket or agricultural market, and volunteer service were negatively associated with levels of dependency: the OR was $0.50(95 \% \mathrm{Cl}, 0.34-0.69, P<$ $0.001) \otimes 0.57(95 \% \mathrm{Cl}, 0.38-0.86, P=0.007)$, and $0.56(95 \% \mathrm{Cl}, 0.40-0.79, P=0.001)$, respectively.

Table 2

The odds ratios of community environment resources and other related risk factors for dependency by logistic regression models

\begin{tabular}{|lllll|}
\hline Variables & Multivariable adjusted & & & \\
\cline { 3 - 5 } & Odds Ratios & $95 \% \mathrm{Cl}$ & Pvalue \\
\hline Received community health services (times) & 1.27 & 1.08 & 1.48 & 0.004 \\
\hline The need for health assessment (n/y) & 2.10 & 1.33 & 3.34 & 0.001 \\
\hline Community geriatric ward (n/y) & 1.97 & 1.23 & 3.18 & 0.005 \\
\hline Short-term care home (n/y) & 2.40 & 1.40 & 4.09 & 0.001 \\
\hline Regular lectures on health knowledge (n/y) & 1.50 & 1.06 & 2.14 & 0.023 \\
\hline Screening for common diseases (n/y) & 1.56 & 1.05 & 2.34 & 0.029 \\
\hline Community cultural activity center (n/y) & 0.49 & 0.34 & 0.69 & $<0.001$ \\
\hline Volunteer Service $(\mathrm{n} / \mathrm{y})$ & 0.57 & 0.38 & 0.86 & 0.007 \\
\hline Supermarket and agricultural market $(\mathrm{n} / \mathrm{y})$ & 0.56 & 0.40 & 0.79 & 0.001 \\
\hline Age (y) & 1.03 & 1.01 & 1.06 & 0.004 \\
\hline Social support (score) & 0.86 & 0.82 & 0.91 & $<0.001$ \\
\hline Chronic disease status (y/n) & 0.71 & 0.52 & 0.96 & 0.027 \\
\hline Income satisfaction $(\mathrm{n} / \mathrm{y})$ & 1.61 & 1.39 & 1.87 & $<0.001$ \\
\hline EPQ scores (points) & 1.13 & 1.09 & 1.17 & $<0.001$ \\
\hline
\end{tabular}

The age-specific results by separated logistic regression models are shown in Table 3. In the group aged under 70 years, the utilization of electronic health records and the need for health assessments, rehabilitation equipment rentals, and community nursing homes were significantly associated with the levels of dependency scores: the OR was $2.81(95 \% \mathrm{Cl}, 1.90-4.14, P<.0001) \varangle 2.25(95 \% \mathrm{Cl}, 1.24-4.06, P=$ 
0.007 ) and $2.13(95 \% \mathrm{Cl}, 1.02-4.43, P=0.043)$, and $1.90(95 \% \mathrm{Cl}, 1.12-3.24, P=0.018)$, respectively. The community cultural activity center and supermarket or agricultural market were negatively associated with levels of dependency.

Table 3

The odds ratios of community environment resources for dependency by the age-specific

\begin{tabular}{|c|c|c|c|c|c|}
\hline & Variables & Multivariable & $95 \% \mathrm{C}$ & & $\begin{array}{l}P \\
\text { value }\end{array}$ \\
\hline & & Odds Ratios & & & \\
\hline $\begin{array}{l}\text { Age } \\
<70\end{array}$ & $\begin{array}{l}\text { Received community } \\
\text { health services }\end{array}$ & 1.26 & 1.03 & 1.55 & 0.024 \\
\hline & $\begin{array}{l}\text { Utilization of electronic } \\
\text { health records }\end{array}$ & 2.81 & 1.90 & 4.14 & $\begin{array}{l}< \\
0.001\end{array}$ \\
\hline & $\begin{array}{l}\text { The need for health } \\
\text { assessment }\end{array}$ & 2.25 & 1.24 & 4.06 & 0.007 \\
\hline & $\begin{array}{l}\text { Rehabilitation equipment } \\
\text { rental }\end{array}$ & 2.13 & 1.02 & 4.43 & 0.043 \\
\hline & Community nursing home & 1.90 & 1.12 & 3.24 & 0.018 \\
\hline & $\begin{array}{l}\text { Community cultural } \\
\text { activity center }\end{array}$ & 0.35 & 0.22 & 0.56 & $\dot{0} 001$ \\
\hline & $\begin{array}{l}\text { Supermarket and } \\
\text { agricultural market }\end{array}$ & 0.57 & 0.38 & 0.85 & 0.006 \\
\hline $\begin{array}{l}\text { Age } \\
\geq \geq\end{array}$ & $\begin{array}{l}\text { Received community } \\
\text { health services }\end{array}$ & 1.49 & 1.18 & 1.88 & $\dot{<} 001$ \\
\hline & Short-term care home & 4.01 & 1.64 & 9.80 & 0.002 \\
\hline & $\begin{array}{l}\text { Day care and nursing } \\
\text { service }\end{array}$ & 2.41 & 1.13 & 5.17 & 0.024 \\
\hline & Transportation service & 1.86 & 1.03 & 3.36 & 0.040 \\
\hline & $\begin{array}{l}\text { Regular lectures on health } \\
\text { knowledge }\end{array}$ & 1.93 & 1.21 & 3.08 & 0.006 \\
\hline & Canteens for the elderly & 0.30 & 0.13 & 0.71 & 0.006 \\
\hline & Volunteer Service & 0.38 & 0.21 & 0.70 & 0.002 \\
\hline & Cafe or tea room & 0.50 & 0.26 & 0.95 & 0.034 \\
\hline & Library & 0.46 & 0.24 & 0.87 & 0.018 \\
\hline
\end{tabular}


In the group aged 70 years and over, a short-term care home was strongly associated with levels of dependency: the OR was $4.01(95 \% \mathrm{Cl}, 1.64-9.80, P=0.002)$. The daycare and nursing service, transportation service, and regular lectures on health knowledge were associated with levels of dependency: the OR was $2.41(95 \% \mathrm{Cl}, 1.13-5.17, \mathrm{P}=0.024), 1.86(95 \% \mathrm{Cl}, 1.03-3.36, \mathrm{P}=0.040)$, and $1.93(95 \% \mathrm{Cl}, 1.21-3.08, \mathrm{P}=0.006)$, respectively. The canteens for the elderly, volunteer service, libraries, and cafes or tea rooms were negatively associated with levels of dependency. The received community health services were positively associated with levels of dependency in the groups aged under as well as over 70 years.

The social support levels-stratified results using the separated logistic regression models are shown in Table 4. The number of times that community health services were received was significantly associated with levels of dependency in both the high level of social support group and the low level of social support group. In the group with a low level of social support, the following were significantly associated with levels of dependency: an emergency call or monitoring system, transportation services, the need for health assessment, and regular lectures on health knowledge: the OR was $2.42(95 \% \mathrm{Cl}, 1.29-4.52, P=$ 0.006), 2.19 ( $95 \% \mathrm{Cl}, 1.18-4.07, P=0.013), 1.89$ (95\% Cl, $1.06-3.36, P=0.031)$, and $1.98(95 \% \mathrm{Cl}, 1.29-$ $3.02, P=0.002)$, respectively. The volunteer service and cafe or tea room were negatively associated with levels of dependency. 
Table 4

The odds ratios of community environment resources for dependency by the social support levelsspecific

\begin{tabular}{|c|c|c|c|c|c|}
\hline & Variables & Multivariable adjusted & $95 \%$ & & $P$ value \\
\hline LSS $^{*}$ & Received community health services & 1.28 & 1.02 & 1.60 & 0.036 \\
\hline & Emergency call or monitoring system & 2.42 & 1.29 & 4.52 & 0.006 \\
\hline & Transportation service & 2.19 & 1.18 & 4.07 & 0.013 \\
\hline & The need for health assessment & 1.89 & 1.06 & 3.36 & 0.031 \\
\hline & Regular lectures on health knowledge & 1.98 & 1.29 & 3.02 & 0.002 \\
\hline & Volunteer Service & 0.44 & 0.25 & 0.76 & 0.004 \\
\hline & Cafe or tea room & 0.30 & 0.17 & 0.51 & $<0.001$ \\
\hline $\mathrm{HSS}^{*}$ & Received community health services & 1.54 & 1.25 & 1.89 & $<0.001$ \\
\hline & Community geriatric ward & 2.37 & 1.24 & 4.53 & 0.009 \\
\hline & Short-term care home & 2.93 & 1.37 & 6.25 & 0.006 \\
\hline & Regular lectures on health knowledge & 1.82 & 1.15 & 2.89 & 0.011 \\
\hline & System of regular visits & 1.95 & 1.25 & 3.06 & 0.004 \\
\hline & Emergency call or monitoring system & 0.40 & 0.21 & 0.77 & 0.006 \\
\hline & Elder university & 0.50 & 0.30 & 0.86 & 0.011 \\
\hline & Supermarket and agricultural market & 0.52 & 0.33 & 0.80 & 0.003 \\
\hline * LSS & ow levels of social support & & & & \\
\hline * HSS & igh levels of social support & & & & \\
\hline
\end{tabular}

In the group with a high level of social support, community geriatric ward, short-term care home, regular lectures on health knowledge, and regular home visits for the elderly who were living alone and disabled were associated with the levels of dependency: the OR was 2.37 ( $95 \% \mathrm{Cl}, 1.24-4.53, P=0.009), 2.93$ (95\% $\mathrm{Cl}, 1.37-6.25, P=0.006), 1.82(95 \% \mathrm{Cl}, 1.15-2.89, P=0.011)$, and $1.95(95 \% \mathrm{Cl}, 1.25-3.06, P=0.004)$, respectively. An emergency call or monitoring system, elder universities, and a supermarket or agricultural market were negatively associated with levels of dependency.

\section{Discussion}


In this study, based on the resource dependence theory, we explored the association between dependency and community environmental resources. Our results showed that the community environment resources were significantly associated with dependency among the elderly. The association between dependency and community environmental resources differed among the elderly by age group and social support level.

The prevalence of dependency steadily increases because of population aging, chronic health conditions, and changes in society [24]. In traditional countries, the family is the main healthcare resource. However, with the change in the world's population structure and social economy, the family is no longer the main healthcare resource $[25,26]$. In addition, studies have shown that dependency can lead to prolonged hospital stays, increases in unnecessary medical costs, and excessive dependence on caregivers that adversely affect their physical and mental health [27]. Although these studies have revealed that dependency can lead to adverse outcomes and consequences, they have not yet explored the improvement strategy by considering the dependency object as the resource demand. The increasing demand from the elderly for complex care requires sustained input from family caregivers or community health or social services to support independent living [28]. Even in resource-rich countries, the demand for home care services has increased. Alternative services have been developed to enable individuals to remain independent in terms of personal care activities if possible or can be provided through the improvement of services. Such services may enhance independence, reduce dependency, and lead to cost reductions $[29,30]$.

In addition, the elderly are usually considered a vulnerable group that is likely to be affected by a poor community environment. A number of studies have reported that the elderly group spends a lot of time in the community and is more dependent on local resources and services than other groups [31]. Community environments might play a major role in supporting healthy aging, and the provision of friendly living environments for the elderly is a public health concern that should be on the agenda of local governments [32]. However, an evidence-based approach is necessary to understand the interactions between community environmental and health demands among the elderly. Therefore, based on the theory of resource dependency, this study used the logistic regression model to quantitatively evaluate the association between community environmental resources and dependency. This analysis showed that a resource-rich community environment was associated with the reduced risk of dependency among the elderly. These resources, such as community cultural activity centers, libraries, cafes or tea rooms, universities for the elderly, supermarkets and agricultural markets, canteens for the elderly, volunteer services, and emergency call or monitoring systems, were negatively associated with dependency.

Several studies have assessed the association between the community environment and the health of the elderly who reside in it but more focused on behaviors, satisfaction with living, and depression [33]. However, the measurements of community environment considerably varied between different research fields. The U.S. Department of Housing and Urban Development developed the Healthy Communities Assessment Tool to assess the community environment from the following three aspects: physical, 
social, and economic roots of community health [34]. The Public Health Agency of Canada established the Age-Friendly Communities Evaluation Guide to evaluate their age-friendly community initiatives [35]. Age-friendly communities help their older residents remain healthy, active, and independent and enable them to make important contributions as they age. The measurable indicators applicable to the eight domains of community life include the 43 items being addressed in age-friendly programming. Studies have shown that physical, social, and psychological environments may affect an individual's mental health and have suggested that the environment may play a particularly important role in the mental health of older adults compared with younger adults. However, studies focusing on dependency and the community environment have paid little attention to other environmental factors or have weak research designs, often without control for confounding variables. In this study, we used the EPQ scale to assess the personality characteristics of the participants, and the association between community environmental factors and dependency was adjusted using the EPQ score, to remove the effect of the important risk factor. Notably, studies have not comprehensively explored this association.

Studies have shown that a high level of social support may reduce the dependency of the elderly [36]. We divided the participants into two groups according to the score of social support. In the low level of social support group, the emergency call monitoring system was significantly associated with a high level of dependency. The common characteristics of the elderly with a low level of social support are that they do not live with their families, have fewer social interactions and outings, have a sense of loneliness, and are often left unattended when ill. Therefore, they must be provided with a system or service to make them feel safe and secure in their own homes. For the elderly with a high level of social support, dependency was associated with short-term care homes. This group prefers to live at home with their families and only uses short-term care temporarily when they are sick or need treatment. Studies have shown that older individuals prefer to live in their homes as their age increases. These results are supported by our findings, that is, with the increasing number of elderly individuals in the community, the demand for shortterm care homes and daycare and nursing services will increase.

Few studies have discussed the association between dependency and community environmental resources from the perspective of resource dependency. One study demonstrated that the understanding of dependency on community services usually has negative characteristics [37]. However, dependency was not a totally negative or positive concept; instead, a gradient exists between negative and positive understandings. Dependency on health services can be described as a positive condition for patients because it helps them feel as if they are in a safe and comfortable place. More recently, dependency on community services has been seen as being on a continuum of more or less autonomy. Moreover, the situation might be an often necessary and helpful temporary phase toward full autonomy. It is the transitory and ever-changing state of dependency on community services that contrasts with a static form of institutional dependency and makes dependency not an entirely negative phenomenon.

With aging, the elderly become more vulnerable to environmental challenges. Additionally, dependency and depression increase with age and are mainly caused by social factors, mostly in vulnerable groups and the elderly with a low social support level [38]. The community environment is particularly important 
for the well-being of the elderly, especially for their mental health [39], for example, living among peers of a similar age Therefore, based on the resource dependency theory, our study's discussion was on the demand for resources. We used quantitative analysis to evaluate the association between dependency and community environmental resources. These results also verify the association between community environmental resources and the mental health of the elderly, and provide a scientific basis for improving community resources and dependency intervention.

This study has several limitations. The association between dependency and community environmental was based on a cross-sectional design; thus, the causality could not be discussed. This complex and changing trend of environmental factors and the change in the association of dependency over time cannot be evaluated and observed. For example, whether the elderly reduce their utilization of and dependency on community primary preventive care service resources by increasing the allocation of elderly-friendly facilities in the community (e.g., community cultural activity centers, elder universities, and cafes or tea rooms) was not confirmed by our study design. In addition, although our study fully considered the community environmental resources' variables and important risk factors, our sample size was too small to evaluate the interactions between the community environment and dependency. Thus, further research is necessary to explore the strategies and effects of improving community environmental dependence.

\section{Conclusions}

This study applied the theory of resource dependence to examine whether the community environment was significantly associated with dependency among elderly individuals. The community primary preventive care service resources were associated with increased levels of dependency, and the community cultural and living facilities were associated with reduced levels of dependency among the elderly in the community. Our results suggest that dependency on community environment resources leads to a combination of negative and positive experiences. Additionally, our results might guide future evaluations of community resources provided by such services, to improve the understanding of what interventions must be implemented to further support the elderly in the community in their lives and promote their autonomy. Through improving the environment, a positive community for the elderly can be created, enabling them to extend the amount of time they can remain in their residence.

\section{Abbreviations}

OARS: Older American Resources and Services

EPQ: Eysenck Personality Questionnaire

ORs: Odds Ratios

\section{Declarations}




\section{Ethics approval and consent to participate}

All participants provided informed consent before participation. The study was approved by the institutional review board at the School of Public Health, Zhejiang University (No: ZGL201909-10).

\section{Consent for publication}

Not applicable.

\section{Availability of data and materials}

The datasets used and/or analyzed during the current study are available from the corresponding author on reasonable request.

\section{Competing interests}

The authors declare no conflict of interest.

\section{Funding}

This study was supported by the basic public welfare project of Zhejiang Province (LGF19H260012), and in part by WeiJiang Special Foundation, Zhejiang University School of Public Health. These foundations provided financial support for this study. These foundations provided financial support for this study.

\section{Authors' contributions}

YL: Conceptualization and design, Funding acquisition, Supervision, Formal analysis, Writing - original draft, YYP: Conceptualization and design, Formal analysis, Writing - original draft, Data collection, YC: Writing - review \& editing, Data collection, PYC: Writing - review \& editing, Data collection, NWL: Writing review \& editing, Data collection.

\section{Acknowledgements}

We thank Xia Gao, Songsong Han, Dongbin Hu and Xuanting Liu for their assistance with survey set up.

\section{References}

1. Beard JR, Officer A, de Carvalho IA, Sadana R, Pot AM, Michel JP, Lloyd-Sherlock P, Epping-Jordan JE, Peeters GMEEG, Mahanani WR, Thiyagarajan JA, Chatterji S. The World report on ageing and health: a policy framework for healthy ageing. Lancet. 2016;387:2145-54.

2. Lee J, Phillips D, Wilkens J, Chien S, Lin YC, Angrisani M, Crimmins E. Cross-Country Comparisons of Disability and Morbidity: Evidence from the Gateway to Global Aging Data. J Gerontol A Biol Sci Med Sci. 2018;73:1519-24. 
3. Chang AY, Skirbekk VF, Tyrovolas S, Kassebaum NJ, Dieleman JL. Measuring population ageing: an analysis of the Global Burden of Disease Study 2017. Lancet Public Health. 2019;4:e159-67.

4. Gusmano MK, Okma KGH. Population Aging and the Sustainability of the Welfare State. Hastings Cent Rep. 2018;48:57-61.

5. Feng ZL. Global Convergence: Aging and Long-Term Care Policy Challenges in the Developing World. J Aging Soc Policy. 2019;31:291-7.

6. Adhikari R, Jampaklay A, Chamratrithirong A. Impact of children's migration on health and health care-seeking behavior of elderly left behind. BMC Public Health. 2011;11:143.

7. Geurtzen N, Keijsers GPJ, Karremans JC, Hutschemaekers GJM. Patients' care dependency in mental health care: Development of a self-report questionnaire and preliminary correlates. J Clin Psychol. 2018;74:1189-206.

8. Alcañiz M, Brugulat P, Guillén M, Medina-Bustos A, Mompart-Penina A, Solé-Auró A. Risk of dependence associated with health, social support, and lifestyle. Rev Saude Publica. 2015;49:26.

9. Kang JI, Hwang SS, Choi JR, Lee ST, Kim J, Hwang IS, Kim HW, Kim CH, Kim SJ. Telomere length in alcohol dependence: A role for impulsive choice and childhood maltreatment. Psychoneuroendocrinology. 2017;83:72-8.

10. Jylhävä J, Jiang M, Foebel AD, Pedersen NL, Hägg S. Can markers of biological age predict dependency in old age? Biogerontology. 2019;2:321-9.

11. Geurtzen N, Keijsers GPJ, Karremans JC, Hutschemaekers GJM. Patients' care dependency in mental health care: Development of a self-report questionnaire and preliminary correlates. J Clin Psychol. 2018;74:1189-206.

12. Tabali M, Ostermann T, Jeschke E, Dassen T, Heinze C. Does the care dependency of nursing home residents influence their health-related quality of life?-A cross-sectional study. Health Qual Life Outcomes. 2013;11:41.

13. Beard JR, Officer A, de Carvalho IA, Sadana R, Margriet PA, Michel JP, Lloyd-Sherlock P, EppingJordan JE, Peeters GMEEG, Mahanani WR, Thiyagarajan JA, Chatterji S. The World report on ageing and health: a policy framework for healthy ageing. Lancet. 2016;387:2145-54.

14. Bornstein RF. Illuminating a neglected clinical issue: societal costs of interpersonal dependency and dependent personality disorder. J Clin Psychol. 2012;68:766-81.

15. Lengen C, Timm C, Kistemann T. Place identity, autobiographical memory and life path trajectories: The development of a place-time-identity model. Soc Sci Med. 2019;227:21-37.

16. Petersen KS, Friis VS, Haxholm BL, Nielsen CV, Wind G. Recovery from mental illness: a service user perspective on facilitators and barriers. Community Ment HIt J. 2015;51:3.

17. Pinfold V. 'Building up safe havens... all around the world': users' experiences of living in the community with mental health problems. Health Place. 2000;6:201-12.

18. Brear M, Hammarberg K, Fisher J. Community participation in research from resource- constrained countries: a scoping review. Health Promot Int. 2018;33:723-33. 
19. More NS, Das S, Bapat U, Alcock G, Manjrekar S, Kamble V, Sawant R, Shende S, Daruwalla N, Pantvaidya S, Osrin D. Community resource centres to improve the health of women and children in informal settlements in Mumbai: a cluster-randomised, controlled trial. Lancet Glob Health. 2017;5:e335-49.

20. Xu X, Zhou L, Antwi HA, Chen X. Evaluation of health resource utilization efficiency in community health centers of Jiangsu Province, China. Hum Resour Health. 2018;16:13.

21. Yu M, Kelley AT, Morgan AU, Duong A, Mahajan A, Gipson JD. Challenges for Adult Undocumented Immigrants in Accessing Primary Care: A Qualitative Study of Health Care Workers in Los Angeles County. Health Equity. 2020;4:366-74.

22. Goodman C, Dening T, Gordon AL, Davies SL, Meyer J, Martin FC, Gladman JR, Bowman C, Victor C, Handley M, Gage H, Iliffe S, Zubair M. Effective health care for older people living and dying in care homes: a realist review. BMC Health Serv Res. 2016;16:269.

23. Matthews FE, Bennett $H$, Wittenberg R, Jagger C, Dening T, Brayne $C$, Cognitive, Function. Ageing Studies (CFAS) collaboration. Who lives where and does it matter? Changes in the health profiles of older people living in long term care and the community over two decades in a high income country. PLoS One. 2016;11:e0161705.

24. Kingston A, Wohland P, Wittenberg R, Robinson L, Brayne C, Fiona EM, Fiona E, Jagger C. Is late-life dependency increasing or not? A comparison of the Cognitive Function and Ageing Studies (CFAS). Lancet. 2017;390:1676-84.

25. Zhang T, Xu Y, Ren J, Sun L, Liu C. Inequality in the distribution of health resources and health services in China: hospitals versus primary care institutions. Int J Equity Health. 2017;16:42.

26. Chokkanathan S, Mohanty J. Health, family strains, dependency, and life satisfaction of older adults. Arch Gerontol Geriatr. 2017;71:129-35.

27. Darbà J, Kaskens L. Relationship between patient dependence and direct medical-, social-, indirect-, and informal-care costs in Spain. Clinicoecon Outcomes Res. 2015;2:387-95.

28. Pripfl J, Körtner T, Batko-Klein D, Hebesberger D, Weninger M, Gisinger C. Social service robots to support independent living: Experiences from a field trial. Z Gerontol Geriatr. 2016;49:282-7.

29. Collerton J, Davies K, Jagger C. Health and disease in 85 year olds: baseline findings from the Newcastle 85 + cohort study. BMJ. 2009;339:b4904.

30. Burns T. The rise and fall of assertive community treatment? Int Rev Psychiatry. 2010;22:130-7.

31. Clarke CS, Round J, Morris S, Kharicha K, Ford J, Manthorpe J, Iliffe S, Goodman C, Walters K. Exploring the relationship between frequent internet use and health and social care resource use in a community-based cohort of older adults: an observational study in primary care. BMJ Open. 2017;7:e015839.

32. Jeste DV, Blazer DG, Buckwalter KC, Cassidy KK, Fishman L, Gwyther LP, Levin SM, Phillipson C, Rao RR, Schmeding E, Vega WA, Avanzino JA, Glorioso DK, Feather J. Age-Friendly Communities Initiative: Public Health Approach to Promoting Successful Aging. Am J Geriatr Psychiatry. 2016;24:1158-70. 
33. Kemperman A, van den Berg P, Weijs-Perrée M, Uijtdewillegen K. Loneliness of Older Adults: Social Network and the Living Environment. Int J Environ Res Public Health. 2019;16:406.

34. U.S. Department of Housing and Urban Development. https://www.usa.gov/federal-agencies/ u-sdepartment-of-housing-and-urban-development.

35. Age-Friendly Communities Evaluation Guide. Using Indicators to Measure Progress. Public Health Agency of Canada. https://www.canada.ca/content/dam/phac-aspc/migration/phac-aspc/ seniorsaines/alt-formats/pdf/indicators-indicateurs-v2-eng.pdf.

36. Alcañizl M, Brugulatll P, GuillénI M, Medina-Bustosll A, Mompart-Peninalll A, Solé-AurólV A. Risk of dependence associated with health, social support, and lifestyle. Rev Saúde Pública. 2015;49:26.

37. Bonavigo T, Sandhu S, Pascolo-Fabrici E, Priebe S. What does dependency on community mental health services mean? A conceptual review with a systematic search. Soc Psychiatry Psychiatr Epidemiol. 2016;51:561-74.

38. Haseda M, Kondo N, Ashida T, Tani Y, Takagi D, Kondo K. Community Social Capital, Built Environment, and Income-Based Inequality in Depressive Symptoms Among Older People in Japan: An Ecological Study From the JAGES Project. J Epidemiol. 2018;28:108-16.

39. Weaver RH, Roberto KA. Home and Community-Based Service Use by Vulnerable Older Adults. Gerontologist. 2017;57:540-51.

\section{Figures}




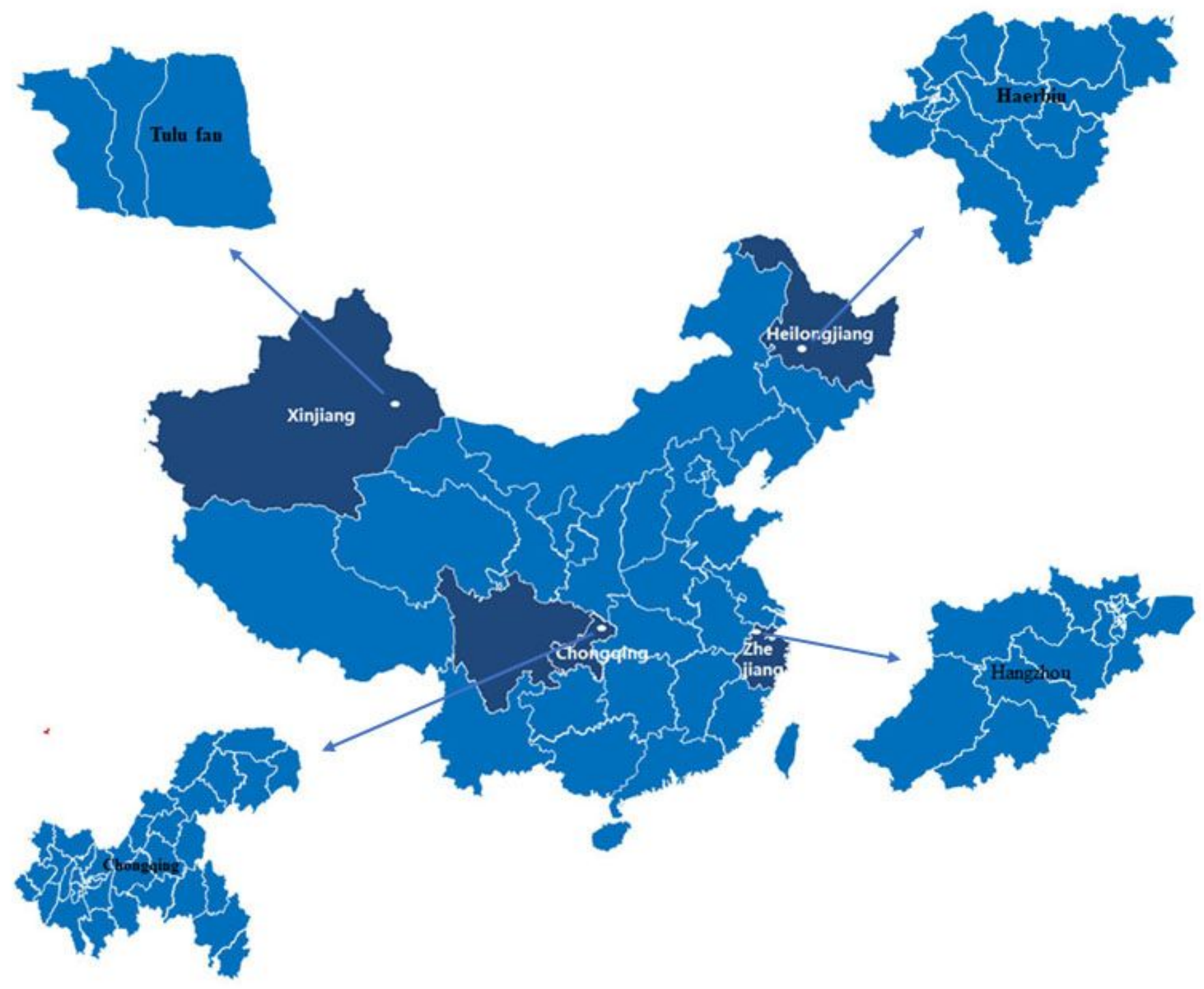

Figure 1

Distribution of study area in China. Resources from: https://www.tocreating.com/ppt/a7kn3.html Note: The designations employed and the presentation of the material on this map do not imply the expression of any opinion whatsoever on the part of Research Square concerning the legal status of any country, territory, city or area or of its authorities, or concerning the delimitation of its frontiers or boundaries. This map has been provided by the authors. 
Providing diet and medication guidance

Family physician contract services dependency scores

Screening for common diseases System of regular visits

Utilization of electronic health records

Regular lectures on health knowledge

The need for health assessment

Received screening or health assessment

Received community health services

Service attitude of the medical staff

Technical level of community medical care Elder university

Community cultural activity center Volunteer Service Indoor cleaning service

Household service

Emergency call or monitoring system

Day care and nursing service

Community geriatric ward

Psychological counseling room

Group home for the elderly with dementia

Short-term care home

Transportation service

Rehabilitation equipment rental

Reemployment assistance

Providing guidance for caregivers

Rehabilitation training and guidance

Nursing of severe chronic diseases

Helping with using the toilet Going out support

Providing meals service

Home-visit bath service

At-home haircut service

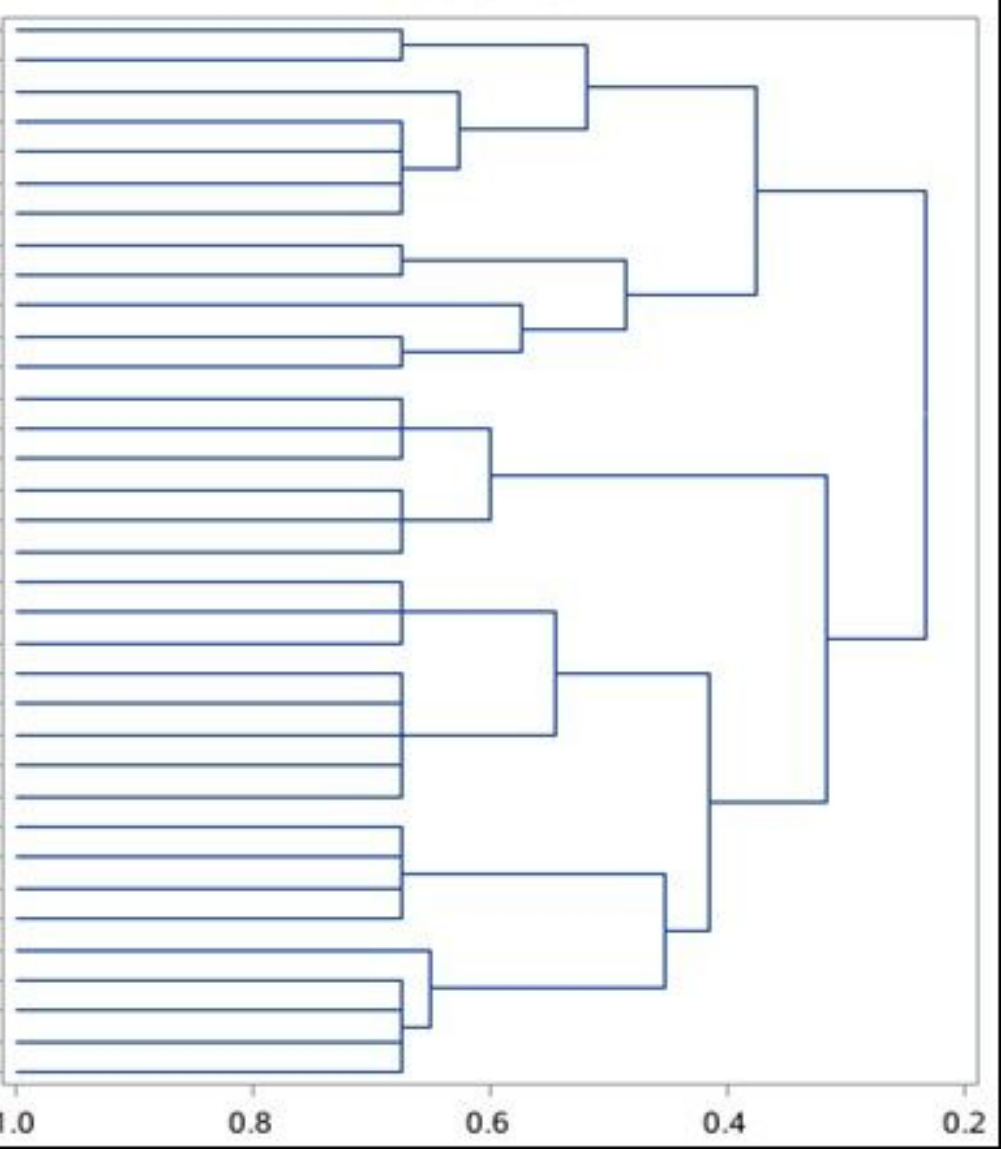

\section{Figure 2}

The tree graph of community environment resources by cluster analysis.

\section{Supplementary Files}

This is a list of supplementary files associated with this preprint. Click to download.

- Questionnaire.doc

- STROBEchecklistv4crosssectional.pdf

- DatainBrief.csv 